\title{
ANL/NDM-68
}

\section{FAST-NEUTRON TOTAL AND SCATTERING CROSS SECTIONS OF ${ }^{103_{R h}}$ *}

$$
\text { by }
$$

\author{
A. B. Smith, P. T. Guenther and J. F. Whalen \\ July 1982
}

*This work supported by the U.S. Department of Energy

$$
\begin{gathered}
\text { Argonne National Laboratory } \\
9700 \text { South Cass Avenue } \\
\text { Argonne, Illinois } \\
\text { USA }
\end{gathered}
$$
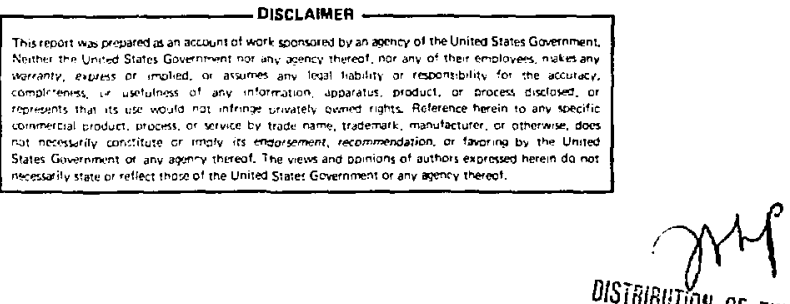


\section{NUCLEAR DATA AND MEASUREMENTS SERIES}

The Nuclear Data and Measurements Series presents results of studies in the fleld of microscopic nuclear data. The primary objective is the dissemination of information in the comprehensive form required for nuclear technology applications. This Series is devoted to: a) measured microscopic nuclear parameters, b) experimental techniques and facilities employed in measurements, $r$ ) the analysis, correlation and interpretation of nuclear data, and d) the evaluation of nuclear data. Contributions to this Series are reviewed to assure technical competence and, unless otherwise stated, the contents can be formally referenced. This Series does not supplant formal journal publication but it does provide the more extensive information required for technological applications (e.g., tabulated numerical data) in a timely manner. 
OTHER ISSUES IN THE ANL/NDM SERIES ARE:

ANL/NDM-1 Cobalt Fast Neutron Cross Sections-Measurement and Evaluation by P. T. Guenther, P. A. Moldauer, A. B. Smith, D. L. Smith and J. F. Whalen, July 1973.

ANL/NDM-2 Prompt Air-Scattering Corrections for a Fast-Neutron Fission Detector: $E_{\mathrm{n}} \leq 5 \mathrm{MeV}$ by Donald L. Smith, September 1973.

ANL/NDM-3 Neutron Scattering from Titanium; Compound and Direct Effects by E. Barnard, J. deVilliers, P. Moldauer, D. Reitmann, A. Smith and $\mathrm{J}$. Whalen, October 1973.

ANL/NDM-4 $90 \mathrm{Zr}$ and $92 \mathrm{Zr}$; Neutron Total and Scattering Cross Sections by P. Guenther, A. Smith and J. Whalen, July 1974.

ANL/NDM-5 Delayed Neutron Data - Review and Evaluation by Samson A. Cox, April 1974.

ANL/NDM-6 Evaluated Neutronic Cross Section File for Niobium by R. Howerton, Lawrence Livermore Laboratory and A. Smith, P. Guenther and J. Whalen, Argonne National Laboratory, May 1974.

ANL/NDM-7 Neutron Total and Scattering Cross Sections of Some Even Isotopes of Molybdenum and the Optical Model by A. B. Smith, P. T. Guenther and J. F. Whalen, June 1974.

ANL/NDM-8 Fast Neutron Capture and Activation Cross Sections of Niobium Isotopes by w. P. Poenitz, May 1974.

ANL/NDM-9 Method of Neutron Activation Cross Section Measurement for $\mathrm{E}_{\mathrm{n}}=$ 5.5-10 MeV Using the $D(d, n) H e-3$ Reaction as a Neutron Source by D. L. Smith and .T. W. Meadows, August 1974.

ANL/NDM-10 Cross Sections for $(n, p)$ Reactions on ${ }^{27} \mathrm{Al}, 46,47,48 \mathrm{Ti}, 54,56 \mathrm{Fe}$, $58 \mathrm{Ni},{ }^{59} \mathrm{Co}$ and ${ }^{64} \mathrm{Zn}$ from Near Threshold to $10 \mathrm{MeV}$ by Ionald L. SmIth and James W. Meadows, January 1975.

ANL/NDM-11 Measured and Evaluated Fast Neutron Cross Sections of Elementa1 Nickel by P. Guenther, A. Smith, D. Smith and J. Whalen, Argonne National Laboratory and $R$. Howerton, Lawrence Livermore Laboratory, JuIy 1975.

ANL/NDM-12 A Spectrometer for the Investigation of Gamma Radiation Produced by Neutron-Induced Reactions by Donald L. Smith, April 1975.

ANL/NDM-13 Response of Several Threshold Reactions in Reference Fission Neutron Fields by Donald L. Smith and James W. Meadows, June 1975.

ANL/NDM-14 Cross Sections for the ${ }^{66} \mathrm{Zn}(\mathrm{n}, \mathrm{p})^{66} \mathrm{Cu}, 1^{113} \mathrm{In}\left(\mathrm{n}, \mathrm{n}^{1}\right)^{11}{ }^{3 \mathrm{~m}} \mathrm{In}$ and $115 \mathrm{In}\left(n, n^{\prime}\right)^{115 m}$ In Reactions from Near Threshold to $10 \mathrm{MeV}$ by Donald L. Smith and James W. Meadows, July 1975. 
ANL/NDM-15 Radiative Capture of Fast Neutrons in ${ }^{165} \mathrm{Ho}$ and 181 Ta by W. P. Poenitz, June 1975.

ANL/NDM-16 Fast Neutron Excitation of the Ground-State Rotational Band of $238 U$ by P. Guenther, D. Havel and A. Smith, September 1975.

ANL/NDM-17 Sample-Size Effects in Fast-Neutron Gamma-Ray Preduction Measurements: Solid-Cylinder Samples by Donald L. Smith, September 1975.

ANL/NDM-18 The Delayed Neutron Yield of $238 \mathrm{U}$ and $241 \mathrm{Pu}$ by J. W. Meadows January 1976.

ANL/NDM-19 A Remark on the Prompt-Fission-Neutron Spectrum of ${ }^{252} \mathrm{Cf}$ by P. Guenther, D. Havel, R. Sjoblom and A. Smith, March 1976.

ANL/NDM-20 Fast-Neutron-Gamma-Ray Production from Elemental Iron: $E_{n} \lesssim$ $2 \mathrm{MeV}$ by Donald L. Smith, May 1976.

ANL/NDM-21 Note on the Experimental Determination of the Relative FastNeutron Sensitivity of a Hydrogenous Scintillator by A. Smith, P. Guenther and R. Sjoblom, June 1976 .

ANL/NDM-22 Note on Neutron Scattering and the Optical Mode1 Near $A=208$ by P. Guenther, D. Havel and A. Smith, September 1976.

ANL/NDM-23 Remarks Concerning the Accurate Measurement of Differential Cross Sections for Threshold Reactions Used in Fast-Neutron Dosimetry for Fission Reactors by Donald L. Smith, December 1976.

ANL/NDM-24 Fast Neutron Cross Sections of Vanadium and an Evaluated Neutronic File by P. Guenther, D. Havel, R. Howerton, F. Mann, D. Smith, A. Smith and J. Whalen, May 1977.

ANL/NDM-25 Determination of the Energy Scale for Neutron Cross Section Measurements Employing a Monoenergetic Accelerator by J.W. Meadows, January 1977.

ANL/NDM-26 Evaluation of the IN-115(N,N')IN-115M Reaction for the ENDF/B-V Dosimetry File by Donald L. Smith, December 1976.

ANL/NDM-27 Evaluated ( $n, p)$ Cross Sections of ${ }^{46} \mathrm{Ti},{ }^{47} \mathrm{Ti}$ and ${ }^{48} \mathrm{Ti}$ by C. Philis and 0 . Bersillon, Bruyeres-1e-Chatel, France and D. Smith and A. Smith, Argonne National Laboratory, January 1977.

ANL/NDM-28 Titanium-II: An Evaluated Nuclear Data File by C. Philis, Centre d'Etudes de Bruytres-le-Chatel, R. Howerton, Lawrence Livermore Laboratory and A. B. Smith, Argonne National Laboratory, June 1977.

ANL/NDM-29 Note on the $250 \mathrm{keV}$ Resonance in the Total Neutron Cross Section of ${ }^{6} \mathrm{Li}$ by A. B. Smith, P. Guenther, D. Have1 and J. F. Whalen, June 1977. 
ANL/NDM-30 Analysis of the Sensitivity of Spectrum-Average Cross Sections to Individual Characteristics of Differential Excitation Functions by Donald L. Smith, March 1977.

ANL/NDM-31 Titanium-I: Fast Neutron Cross Section Measuremencs by P. Guenther, D. Have1, A. Smith and J. Whalen, May 1977.

ANL/NDM-32 Evaluated Fast Neutron Cross Section of Uranium-238 by W. Poenitz, E. Pennington, and A. B. Smith, Argonne National Laboratory and $R$. Howerton, Lawrence Livermore Laboratory, October 1977.

ANL/NDM-33 Comments on the Energy-Averaged Total Neutron Cross Sections of Structural Materials by A. B. Smith and J. F. Whalen, June $19 / 7$.

ANL/NDM-34 Graphical Representation of Neutron Differential Cross Section Data for Reactor Dosimetry Applications by Donald L. Smith, June 1977.

ANL/NDM-35 Evaluated Nuclear Data File of Th-232 by J. Meadows, W. Poenitz, A. Smith, D. Smith and J. Whalen, Argonne National Laboratory and R. Howerton, Lawrence Livermore Laboratory, February 1978.

ANL/NDM-36 Absolute Measurements of the $233 \mathrm{U}(\mathrm{n}, \mathrm{f})$ Cross Section Between 0.13 and $8.0 \mathrm{MeV}$ by W. P. Poenitz, April 1978 .

ANL/NDM-37 Neutron Inelastic Scattering Studies for Lead-204 by D. L. Smith and J. W. Meadows, December 1977.

ANL/NDM-38 The Alpha and Spontaneous Fission Half-Lives of $242 \mathrm{Pu}$ by J. W. Meadows, December 1977.

ANL/NDM-39 The Fission Cross Section of 239 Pu Relative to $235 \mathrm{U}$ from 0.1 to $10 \mathrm{MeV}$ by J. W. Meadows, March 1978.

ANL/NDM-40 Statistical Theory of Neutron Nuclear Reactions by P. A. Moldauer, February 1978.

ANL/NDM-41 Energy-Averaged Neutron Cross Sections of Fast-Reactor Structural Materials by A. Smith, R. McKnight and D. Smith, February 1978.

ANL/NDM-42 Fast Neutron Radiative Capture Cross Section of 232 Th by W. P. Poenitz and D. L. Smith, March 1978.

ANL/NDM-43 Neutron Scattering from $12 \mathrm{C}$ in the Few-MeV Region by A. Smith, R. Holt and J. Whalen, September 1978.

ANL/NDM-44 The Interaction of Fast Neutrons with $60 \mathrm{Ni}$ by A. Smith, P. Guenther, D. Smith and J. Whalen, January 1979.

ANL/NDM-45 Evaluation of $235 \mathrm{U}(\mathrm{n}, \mathrm{f})$ between $100 \mathrm{KeV}$ and $20 \mathrm{MeV}$ by $\mathrm{W} . \mathrm{P}$. Poenitz, July 1979. 
ANL/NDM-46 Fast-Neutron Total and Scattering Cross Sections of 107 Ag in the MeV Region by A. Sulth, P. Guenther, G. Winkler and J. Whalen, January 1979.

ANL/NDM-47 Scattering of MeV Neutrons from Elemental Iron by A. Smith and P. Guenther, March 1979.

ANL $/$ NDM-48 $235 \mathrm{U}$ Fission Mass and Counting Comparison and Standardization by W. P. Poenitz, J. W. Meadows and R. J. Armant, May 1979.

ANL/ND:i-49 Some Comments on Resolution and the Analysis and Interpretation of Experimental Results from Differential Neutron Measurements by Donald L. Smith, November 1979.

ANL/NDM-50 Prompt-Fission-Neutron Spectra of $233 \mathrm{U}, 235 \mathrm{U}, 239 \mathrm{Pu}$ and ${ }^{240} \mathrm{Pu}$ Relative to that of $252 \mathrm{Cf}$ by A. Smith, P. Guenther, G. Winkler and R. McKnight, September 1979.

ANL/NDM-51 Measured and Evaluated Neutron Cross Sections of Elemental Bismuth by A. Smith, P. Guenther, D. Sutth and J. Whalen, April 1980.

ANL/NDM-52 Neutron Total and Scattering Cross Sections of ${ }^{6} \mathrm{Li}$ in the Few $\mathrm{MeV}$ Region by P. Guenther, A. Smith and J. Whalen, February 1980.

ANL/NDM-53 Neutron Source Investigations in Support of the Cross Section Program at the Argonne Fast-Neutron Generator by James W. Meadows and Donald L. Smith, May 1980.

ANL/NDM-54 The Nonelastic-Scattering Cross Sections of Elemental Nickel by A. B. Smith, P. T. Guenther and J. F. Whalen, June 1980.

ANL/NDM-55 Thermal Neutron Calibration of a Tritlum Extraction Facility using the ${ }^{6} \mathrm{Li}(\mathrm{n}, \mathrm{t})^{4} \mathrm{He} /{ }^{197} \mathrm{Au}(\mathrm{n}, \mathrm{Y})^{198} \mathrm{Au}$ Cross Section Ratio for Standardization by M. M. Bretscher and D. L. Smith, August 1980.

ANL/NDM-56 Fast-Neutron Interactions with $182 \mathrm{~W}, 184 \mathrm{~W}$ and $186 \mathrm{~W}$ by P. T. Guenther, A. B. Smith and J. F. Whalen, December 1980.

ANL/NDM-57 The Total, Elastic- and Inelastic-Scattering Fast-Neutron Cross Sections of Natural Chromium, Peter T. Guenther, Alan B. Smith and James F. Whalen, January 1981.

ANL/NDM-58 Review of Measurement Techniques for the Neutron Capture Process by W. P. Poenitz, August 1981 .

ANL/NDM-59 Review of the Importance of the Neutron Capture Process in Fission Reactors, Wolfgang P. Poenitz, July 1981.

ANL/NDM-60 Neutron Capture Activation Cross Sections of ${ }^{94} \mathrm{Zr},{ }^{96} \mathrm{Zr},{ }^{98}, 100 \mathrm{Mo}$, and $110,114,116 \mathrm{Cd}$ at Thermal and $30 \mathrm{keV}$ Energy, John M. Wyrick and Wolfgang P. Poenitz, (to be published). 
ANL/NDM-61 Fast-neutron Total and Scattering Crose Sections of $58_{\text {Ni }}$ by Car1 Budtz-Jorgensen, Peter T. Guenther, Alan B. Smith and James F. Whalen, September 1981.

ANL/NDM-62 Covariance Matrices and Applications to the Fleld of Nuclear Data, by Donald L. Sinith, November 1981.

ANL/NDM-63 On Neutron Inelastic-Scattering Cross Sections of ${ }^{232} \mathrm{Th},{ }^{23} \mathrm{U}$,

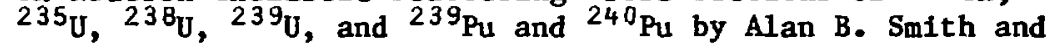
Peter T. Guenther, January 1982.

ANL/NDM-64 The Fission Fragment Angular Distributions and Total Kinetic Energies for $235_{U}(n, f)$ from .18 to $8.83 \mathrm{MeV}$ by James $W$. Meadows, and Carl Budtz-Jørgensen, (to be published).

ANL/NDM-65 Note on the Elastic Scattering of Several MeV Neutroils from Elemental Calcium by Alan B. Smith and Peter T. Guenther, March 1982.

ANL/NDM-66 Fast-neutron Scattering Cross Sections of Elemental Silver by Alan B. Smith and Peter T. Guenther, May 1982.

ANL/NDM-67 Non-evaluation Applications for Covariance Matrices by Donald L. Smith, May 1982. 


\section{TABLE OF CONTENTS}

$\underline{\text { Page }}$

Abstract ............................. . . 1

I. Introduction ....................... 2

II. Experimental Methods . . . . . . . . . . . . . . . 2

III. Experimental Results . . . . . . . . . . . . . . 2

IV. Interpretation . . . . . . . . . . . . . . . 8

V. Comparisons with ENDF/B-V .................. 10

VI. Summary Comment . . . . . . . . . . . . . . . . 10

Acknowledgements . . . . . . . . . . . . . . . . 12

References ........................ 13 
FAST-NEUTRON TOTAL AND SCATTERING CROSS SECTIONS OF ${ }^{103}$ Rh*

by

A. B. Sinth, P. T. Guenther and J. F. Whalen

Argonne National Laboratory

Argonne, Illinois

Abstract

Fast-neutron total cross sections of ${ }^{103} \mathrm{Rh}$ are measured with 30 to $50 \mathrm{keV}$ resolutions from 0.7 to $4.5 \mathrm{MeV}$. Differential elastic- and inelastic-scattering cross sections are measured from 1.45 to $3.85 \mathrm{MeV}$. Scattered-neutron groups corresponding to excited levels at $334 \pm 13,536 \pm 7,648 \pm 25,796 \pm 20$, $864 \pm 22,1120 \pm 22,1279 \pm 50,1481 \pm 27,1683 \pm 39,1840 \pm 79,1991 \pm 71$ and 2050 (tentative) $\mathrm{keV}$ are observed. An optical-statistical model is derived from the elastic-scattering results. The experimental values are compared with comparable quantities given in the ENDF/B-V evaluation.

*This work supported by the U.S. Department of Energy. 


\section{INTRODUCTION}

This is the third report of a series dealing with the interaction of fasi-neutrons with fission-product targets. Similar studies of palladium and silver are described In Refs. 1 and 2, respectively. The primary objectives of these studies were; 1 ) the determination of neutron cross sections in the low-MeV region for the derivation of an optical-statistical model (OM) suitable for the quantitative prediction of the interaction of fast neutrons with difficult-to-measure fission-product nuclel of s1milar mass, and 2) the provision of experimental information directly relevant to fission-product nucle1. Generalization of the individual OM parameter sets w111 be discussed in Ref. 3. The primary emphasis was on neutron total and elastic-scattering cross sections and, secondarily, on inelastic-scattering cross sections. Elemental rhodium is monoisotopic $(103 \mathrm{Rh})$. It lies near the extreme peak of the light-mass fission-product-yield curve with, for example, a fission-product yield of $\approx 5.85 \%$ for the fission of $239 \mathrm{Pu}$ induced by fission-spectrum neutrons ( $1 . e$. by neutrons of energies similar to those encountered in a typlcal fast-breeding reactor).

Subsequent portlons of this report deal with the experfmental results, and their interpretation in terms of an $O M$, and with some comparisons with the corresponding values given in $\mathrm{ENDF} / \mathrm{B}-\mathrm{V}^{4}$.

\section{EXPERIMENTAL METHODS}

All of the measurements employed a $2 \mathrm{~cm} 1 \mathrm{n}$ dlameter and $2 \mathrm{~cm}$ long cylinder of metallic rhodium. Chemlcal impurities within the sample were negligible. The sample density was determined to better than $1 \%$ by means of preclsion welght and dimension measurements. All neutron measurements were made using the ${ }^{7} \mathrm{LI}(\mathrm{p}, \mathrm{n})^{7} \mathrm{Be}$ reaction as a neutron source operating $1 \mathrm{n}$ the nsec-pulsed mode with associated time-of-flight techniques. The neutron total-cross-section measurements were carried out with the Argonne total-crosssection apparatus. The neutron differential-scattering measurements were made with the Argonne ten-angle time-of-flight system. The methods and apparatuses employed in both types of measurements were identical to those described in Refs. 1 and 2 and, indeed, the measurements were made concurrently with the palladium measurements of Ref. 1 .

\section{EXPERIMENTAL RESULTS}

\section{A. Neutron Total Cross Sections}

Neutron total cross sections were measured from $\approx 0.7$ to $4.5 \mathrm{MeV}$ at intervals of $\lesssim 50 \mathrm{keV}$ using monoenerget1c-source techniques with resolutions in the range of 30 to $50 \mathrm{keV}$. The objective was the determination of energy-averaged total cross sections consistent with the concept of the OM. The measurements were made in several sets, each spanning the 
experimental energy range. The results from the various sets were combined and averaged over $100 \mathrm{keV}$ energy bins. The statistical uncertainties of the averaged values were $\lesssim 1 \%$. Corrections were made for small dead-time effects. In-scattering and self-shielding corrections were negligible in the present experiments. The energy-averaged results are shown in Fig. 1. The present energy-averaged results decrease smoothly in magnitude with energy without any indication of energy-dependent fluctuations. The present values are in good agreement with recent results of white-source measurements by Poenitz et al. 5 and the latter were used to extend the present measirements to lower energies as illustrated in Fig. 1. Concurrently with the rhodium measurements, neutron total cross sections of carbon were determined giving results in good agreement with those reported in the literature. ${ }^{6}$

\section{B. Neutron Elastic-Scattering Cross Sections}

Differential elastic-scattering cross sections were measured from $\approx 1.45$ to $3.85 \mathrm{MeV}$. Below $3.0 \mathrm{MeV}$ the measurements were made at $\approx 50 \mathrm{keV}$ intervals and at ten scattering angles distributed between $\approx 20$ and 160 degrees. At $3.0 \mathrm{MeV}$ and above the measurements ware made at $\approx 100 \mathrm{keV}$ intervals and twenty scattering angles distributed over the same angular range. The objective was reliable encrgy-average cruss sections, thus broad $(\approx 30$ to $70 \mathrm{keV}$ ) resolutions were employed in the measurements and, below $3.0 \mathrm{MeV}$, results obtained at adjacent energies were averaged. The broad experimental resolutions contributed to an energy-smooth cross-section behavior and good statistical accuracies but precluded the resolution of elastic-scattered neutrons from inelastic-scattered neutrons associated with the excitation of the first two levels at $\approx 39$ and $93 \mathrm{keV}$. Thus it should be clearly understood that, the measured "elastic" cross sections referred to here are inclusive of two small inelastic-neutron components. The latter are dealt with in the interpretation described below. The differential neutron scattering measurements were made relative to the neutron total cross sections of carbon $^{6}$ in the manner described in Ref. 8 . Neutron scattering angles were determined to a relative uncertainty of \pm 0 . . degree and an absolute uncertainty of \pm 0.75 degree. The statistical uncertainties of the individual differential elastic-scattering cross sections was $\lesssim 1 \%$ with larger uncertainties at the extreme miminum of the distributions. Systematic differential-cross-section uncertainties, largely associated with detector calibration, were $\approx 3 \%$. The measured results were corrected for multiple-event, beam-attenuation and angular-resolution effects using the correction procedures of Ref. 9. Generally, these correction procedures introduced a $1 \%$ uncertainty into the cross-section values. Thus the overall differential-cross-section uncertainty was $\lesssim 5 \%$.

The measured differential "elastic"-scattering results are summarized in Fig. 2. These differential values were least-square fitted with $6^{\text {th-order }}$ Legendre-Polynomial series in order to obtain the angle-integrated elastic scattering cross sections shown in Fig. 1 . The quality of the Legendrepolynomial description of the differential values is indicated by the curves of Fig. 2. The uncertainties of the angle-integrated cross sactions are $\lesssim 5 \%$. The present elastic-scattering results reasonably extrapolate to the lower-energy values of Ref. 7 as illustrated in Fig. 1. 


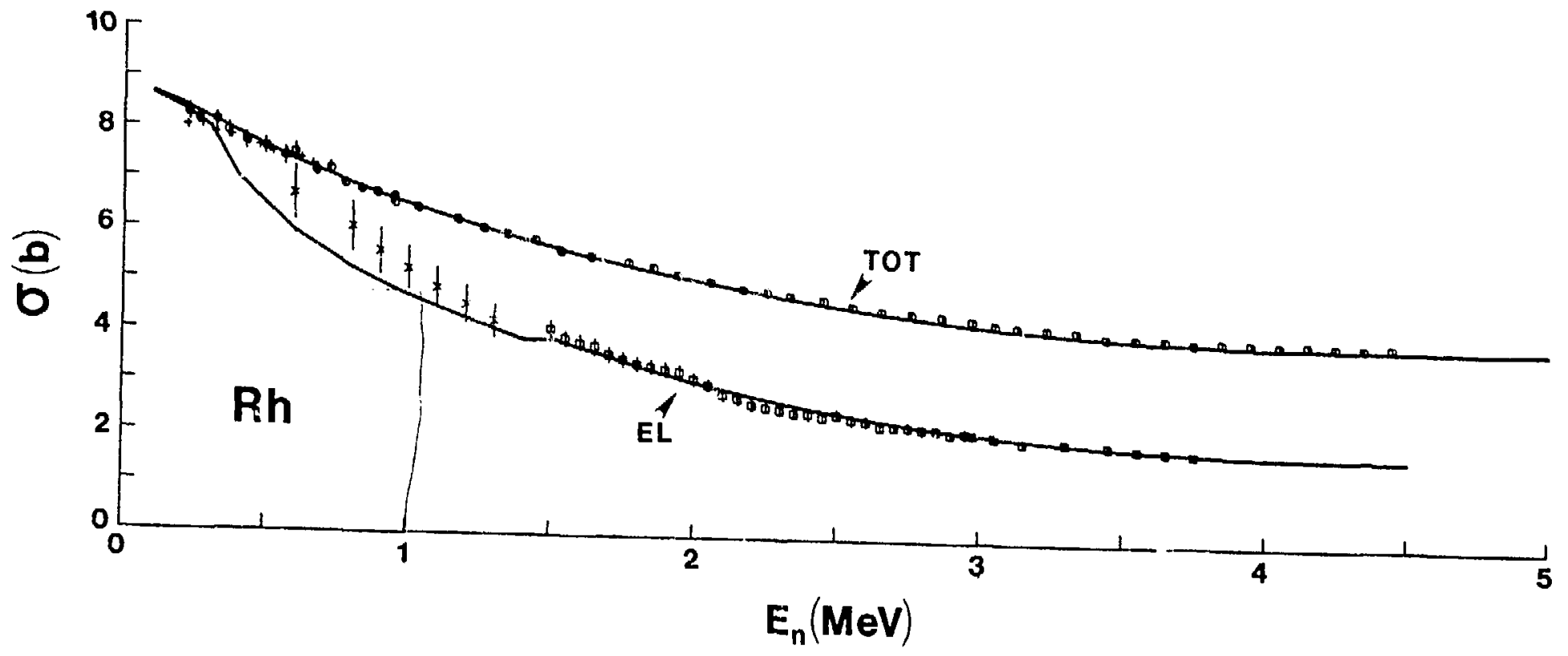

Fig. 1. Neutron Total and "Elastic"-Scattering Cross Sections of $103_{\mathrm{Rh}}$. The present experimental results are indicated by 0 (totals) and $D$ (elastic-scattering) symbols. Total-cross-section results are extended to energies below $700 \mathrm{keV}$ using values of Ref. 5. Lower-energy elastic scattering results of Ref. 7 are indiated by $X$ symbols. Curves indicate the results of OM calculations as described in the text. 


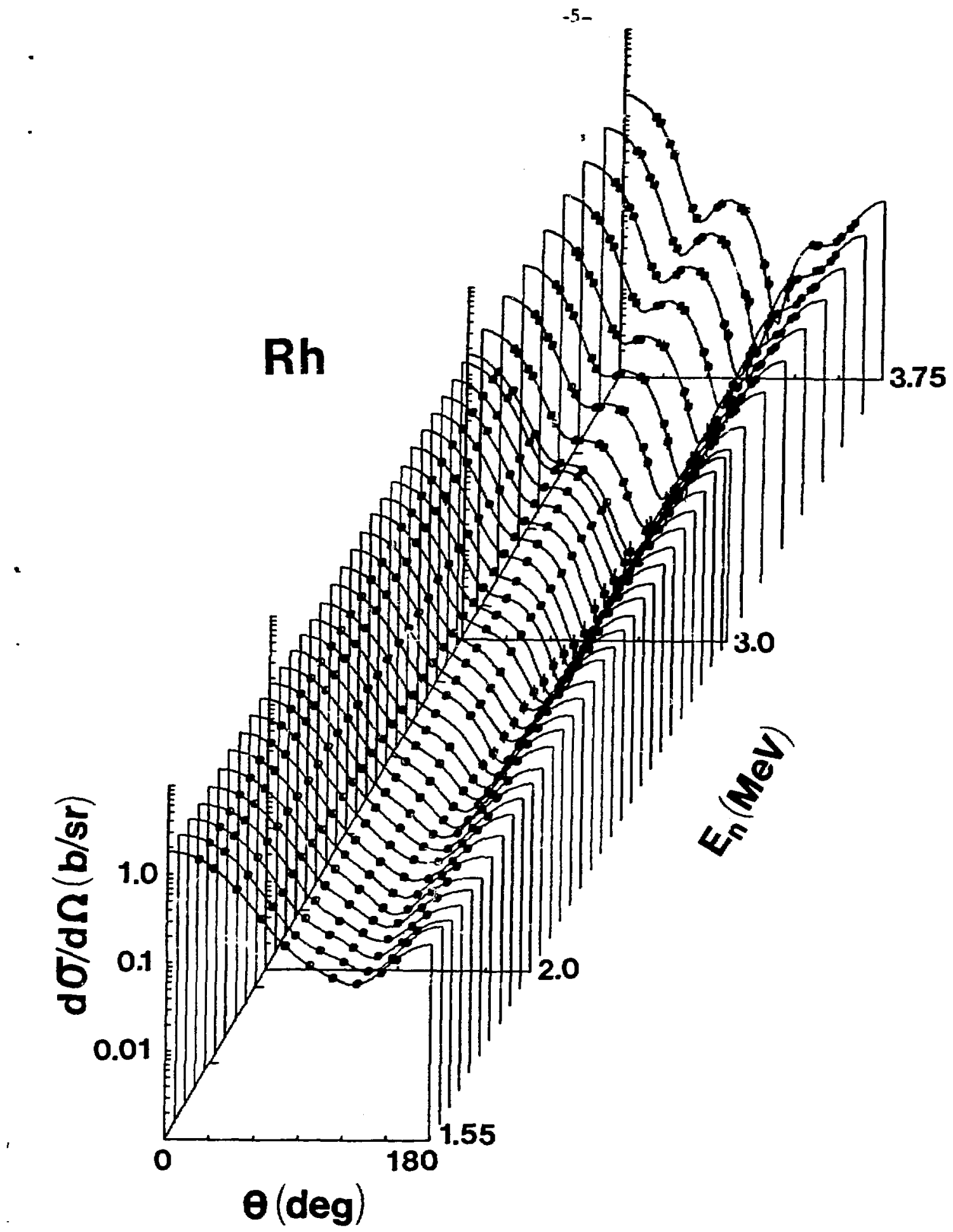

Fig. 2. Differential "Elastic"-Scattering Cross Sections of $103_{\mathrm{Rh}}$. The present exper1mental results are indicated by data symbols. Curves Indicate results of fitting Legendre-Polynomial series to the measured values. 


\section{Neutron Inelastic-Scattering Cross Sections}

The primary goal of the measurements was the determination of neutron total and elastic-scattering cross sections. However, inelastic-scattering cross sections were acrude in the course of the "elastic"-scattering measurements. The intentionally-broad incident-energy spreads precluded the resolution of neutrons associated with the excitation of the low-lying 39 and $93 \mathrm{keV}$ levels (as noted above), and restricted the resolution of inelasticneutron groups corresponding to the excitations of higher-lying levels. Twelve inelastic-neutron groups were observed corresponding to the excitations of levels up to $\approx 2.0 \mathrm{MeV}$ as summarized in Table 1 . In only two of these cases could the observed excitations be reasonably attributed to a single level. The remainder appear to be composites of contributions from two or more levels. Further definition of these components will be pursued in future measurements to be reported elsewhere.10 The observed excitation energies of Table $I$ are simple averages of results of a number of measurements with the uncertainties defined as the RMS deviations of the observables from the averages. Thus the uncertainties apply to the mean excitation energies and do not necessarily correspond to scattered-neutron resolutions. The latter were governed by the incident-neutron energy spreads and the scatteredneutron resolutions of the apparetus. Generally, the observed excitation energies are reasonably consistent with the detalled level structure determined by me.sns of $\left(n ; n^{\top}, y\right)$ measurements ${ }^{7}$ and radioactive decay studies ${ }^{11}$ up to $\approx 1300 \mathrm{keV}$ (see Table 1). Knowledge of higher-energy levels remains very fragmentary.

Inelastic-scattering cross-section determinations extended in incident energy from $\approx 800 \mathrm{keV}$ above threshold to $3.85 \mathrm{MeV}$. The measured differential values were corrected for multiple-event and beam-attenuation effects. Angle-integrated inelastic-scattering cross sections were derived from the measured differential values in the same manner as described above in the context of elastic scattering. The inelastic-scattered neutron distributions approached isotropy, thus the Legendre-Polynomial Series fitted to the measured values were of low order (e.g., $\leq 2)$. The origins of the uncertainties in the resulting cross sections were analogous to those for elastic scattering (above) with generally much larger statistical components. An additional uncertainty factor was the second neutron group from the ${ }^{7} \mathrm{LI}(p ; n)^{7}$ Be source reaction. This contibution was particularly a concern for the excitation of the $334 \mathrm{keV}$ level where, over much of the measured energy range, the elastically-scattered second-group component was not resolved from the inelastic-neutron first-group. The requisite corrections for the second-source-neutron group increased the inelastic-cross-section uncertainties for a number of the excitations. Generally, the total inelastic-scattering cross-section uncertainties were in the range 10 to more than 30\%. The experimental inelastic-scattering cross sections results are summarlzed in Fig. 3. Cross sections for the excitation of 796 and 864 $\mathrm{keV}$ levels are given as a composite sum in order to enhance accuracies. The figure also contains "eyeguides" for each excitation indiciting energy-dependent trends. The sum of these "eyeguides" is consistent with the measured neutron total and elastic-scattering results discussed above. Also, the present inelastic-scattering results are reasonably consistent with the better resolution and lower-energy results of Ref. 7 . 


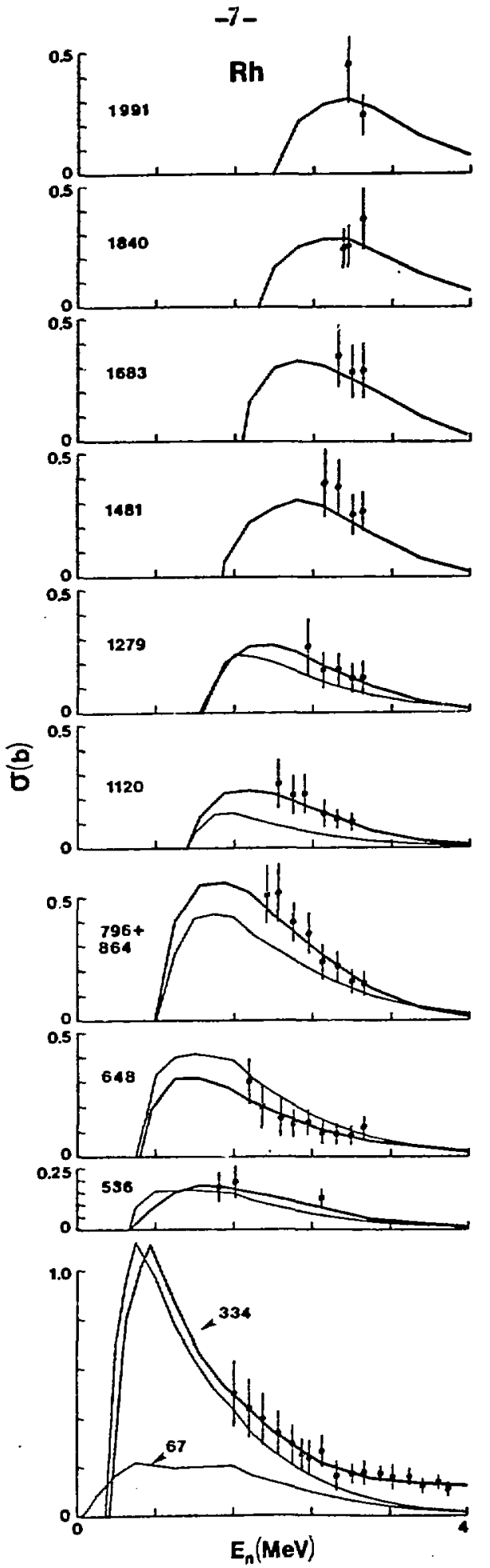

Fig. 3. Neutron Inelastic-Scattering Cross Sections of $103 \mathrm{Rh}$. Observed excitation energies are numerically given in the various sections of the figure. The present experimental results are indicated by circular data symbols. Heavy curves are "eyeguides" constructed through the measured values. Light curves indicate the results of model calculations as discussed in the text. 


\section{INTERPRETATION}

It was assumed that the fast-neutron interaction with ${ }^{103} \mathrm{Rh}$ could be described by a spherical optical-statistical model (OM) ${ }^{12}$. The 04 parameters were deduced from the observed differential elastic-scattering cross sections (see Fig. 1) by concurrently chi-square fitting the entire data base. The fitting proced ire simultaneously varied the six OM parameters; real and Imaginary strengths, radil and diffusenesses. The real strength was assumed to have an energy dependence of the form $V=V_{0}-0.3 \times \mathrm{E}(\mathrm{MeV})$, consistent with commonly used global potentials ${ }^{13}$. Compound-nucleus (CN) processes wera calculated using the Hauser-Feshbach formula ${ }^{14}$ as modffied by Moldauer ${ }^{15}$. The excitation of 17 discrete levels to energies of $\approx 1.4 \mathrm{MeV}$ was considered using the energles and $J-\pi$ values of Ref. 7 , supplemented by the compilation of Ref. 11. Higher-lying levels were statistically described using the parameters of Gilbert and Cameron ${ }^{16}$. All of the calculations were made with the computer code ABAREX ${ }^{17}$. This code is capable of fitting observed differential cross sections consisting of several components. That capability was utilized as the observed "elastic"-scattering cross sections included inelastic contributions associated with the excitation of $40 \mathrm{key}$ $(7 / 2+)$ and $93 \mathrm{keV}(9 / 2+)$ levels. These Inelastic components made a small but significant contribution to the observed differential elastic-scattering cross sections results.

Following the above procedures, the OM parameters of Table 2 were obtained. The real and imaginary strengths (measured as integral per nucleon, $\mathrm{J}_{\mathrm{v}} / \mathrm{A}$ and $J_{w} / A$, or $V r^{2}$ and $W \cdot a$, respectively) are similar to those generally applicable in this mass-energy region ${ }^{3}$. The imaginary radius is somewhat larger than the real radius as is found in potentials largely based on low-energy strength functions ${ }^{18}$. The parameters of Table 2 provide a gocd description of the observed differential "elastic"-scattering cross sections as illustrated in Fig. 4. They also nicely describe the observed neutron total and angle-integrated "elastic"-scattering cross sections as illustrated in F1g. 1. The small discontinuity in the elastic-scattering cross section near $1.5 \mathrm{MeV}$ is due to the inclusion of the first two inelastic-scattering components to make the calculated and observed results consistent. The calculations indicate smaller low-energy elastic-scattering values than reported in Ref. 7.

Comparison of measured and calculated inelastic-scattering cross sections are complicated by the limited knowledge of excited levels and by the lack of experimental definition. However, measured and calculated results are compared to excitation energies of $\approx 1200 \mathrm{keV}$ in Fig. 3. Cross sections calculated for the composite excitation $\left(\overrightarrow{\mathrm{E}}_{\mathrm{x}}=67 \mathrm{keV}\right)$ of the $40 \mathrm{keV}(7 / 2+)$ and 93 $\mathrm{keV}(9 / 2+)$ levels are indicated. There is no counterpart in the present measurements. The cross sections for the excitation of the $334 \mathrm{keV}$ level (295 kev (3/2-) and $357 \mathrm{keV}(5 / 2-)$ ) are large. The calculated values are somewhat smaller than the measured results and increasingly so with energy. The measured values are not particularly well known due to corrections for contributions from the second-neutron group of the source reaction. However, the discrepancy is systematic and has the character and magnitude of a directvibrational process not consistent with a $\mathrm{CN}$ model. A similar behavior was noted in studies of the neutron interaction with silver as discussed in Ref. 2. 


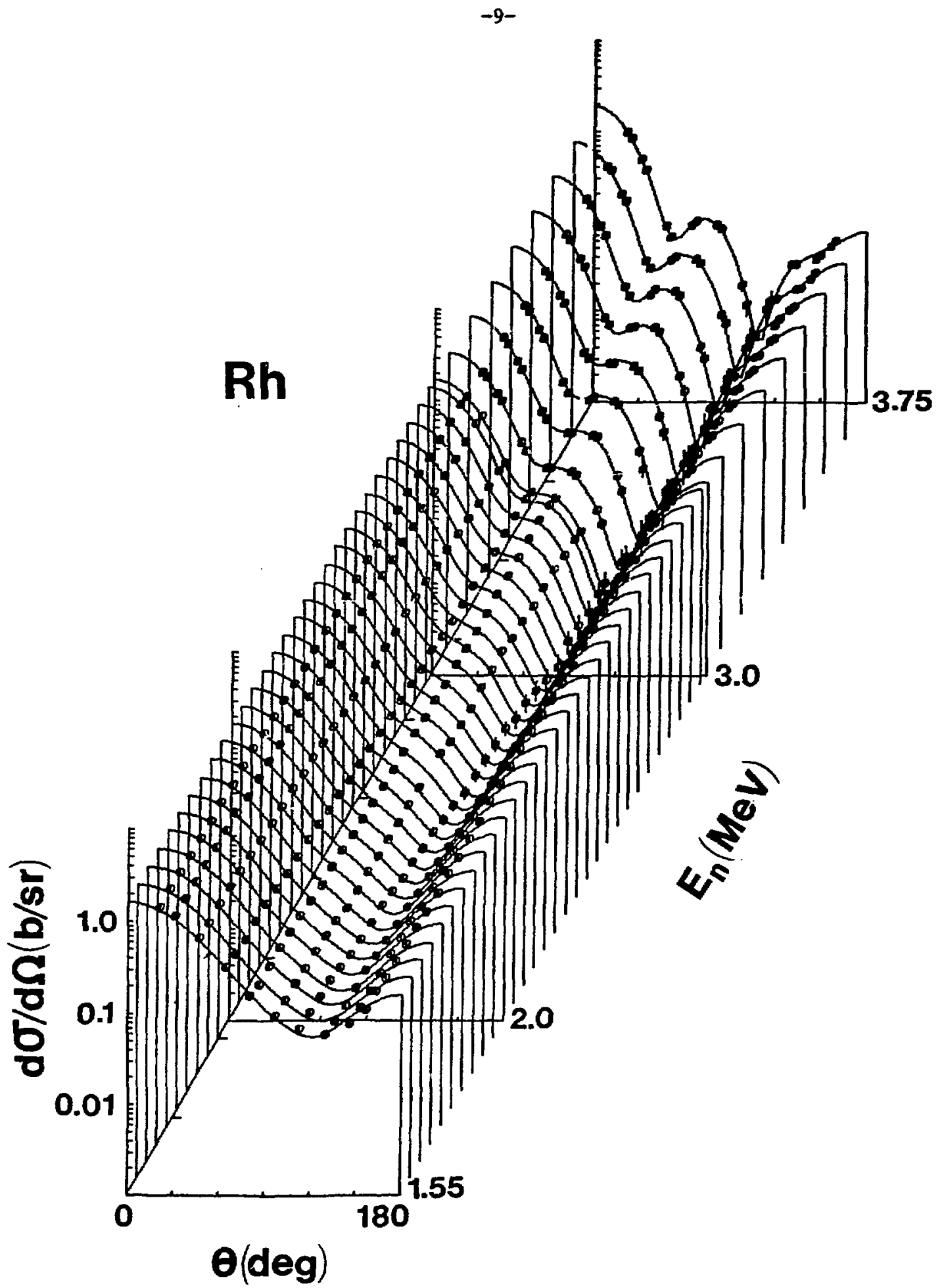

Fig. 4. Measured and Calculated Differential "Elastic"-Scattering Cross Sections of $103_{\mathrm{Rh}}$. Measured results are indicated by data symbols and calculated values by curves. 
The cross sections for the excitation of the $536 \mathrm{keV}(5 / 2+)$ level are small and there is reasonable agreement between measurement and calculation. The calculated cross sectio ', for the excitation of the $648 \mathrm{keV}(607(7 / 2+), 650$ $\operatorname{keV}(5 / 2+)$ and $651 \mathrm{keV}(3 / \angle t))$ level are marginally larger than the observed values. Calculated cross sections for hjgher-lying levels are universally smaller than the measured values. This discrepancy may be partly attributable to inappropriate $J-\pi$ assignments and/or the omission of contributing levels in the calculations. The measured values are not definitive enough to effectively test either of these premises. Inappropriate statistical-1evel parameters may also be a concern but the usual symptom of incorrect channel competition are not in evidence.

\section{COMPARISONS WITH ENDF/B-V}

The prominent measured cross sections were compared with the corresponding values given in ENDF/B-V(MAT-1310)4. The evaluated neutron total cross sections are generally larger than the measured quantities as illustrateo in Fig. 5 and Table 3 . The differences range from small anounts (e.g., $\approx 1 \%$ ) to as much as $8 \%$. It is not clear to what extent a model played a part in the evaluation. If it was a significant consideration its parameters were not capable of reasonably describing the measured total cross sections over the 1 to $3 \mathrm{MeV}$ region and the neutron total cross sections is the most readily calculated observable. The evaluated elastic-scattering cross sections are also generally bigger than the measured values by even larger amounts $(\approx 15 \%$ at $\approx 2.5 \mathrm{MeV}$ ), as illustrated in Fig. 5 and Table 3. The nonelastic cross sections implied by the measurements are in good agreement with the evaluated total inelastic-scattering cross sections as illustrated in Fig. 5 . This agreement maybe somewhat fortuitous in view of the discrepancles between measured and evaluated neutron total and elastic-scattering cross sections.

\section{SUMMARY COMMENT}

The present measurements provide new definition of the ${ }^{103} \mathrm{Rh}$ neutron total cross sections in a region where previous knowledge was sparse or non-existant. The differential neutron "elastic"-scattering measurements provide a good knowledge of the "elastic"-scattering process in the low-MeV region. The observations provide some understanding of the neutron inelastic-scattering process but lack the resolution necessary to define the detailed excited-level structure. The elastic-scattering data was used to deduce a spherical OM potential, the parameters of which are consistent with those found generally applicable in this mass-energy region ${ }^{3}$. This potential provides a vehicle for the calculation of other neutron-induced processes (e.g., radiative capture) and/or for the extrapolation to nearby experimentally inaccessable fission products. The experimental results suggest that the evaluated neutron total and elastic-scattering cross sections as given in ENDF/B- $V^{4}$ are too large by significant amounts throughout the few-MeV region. 


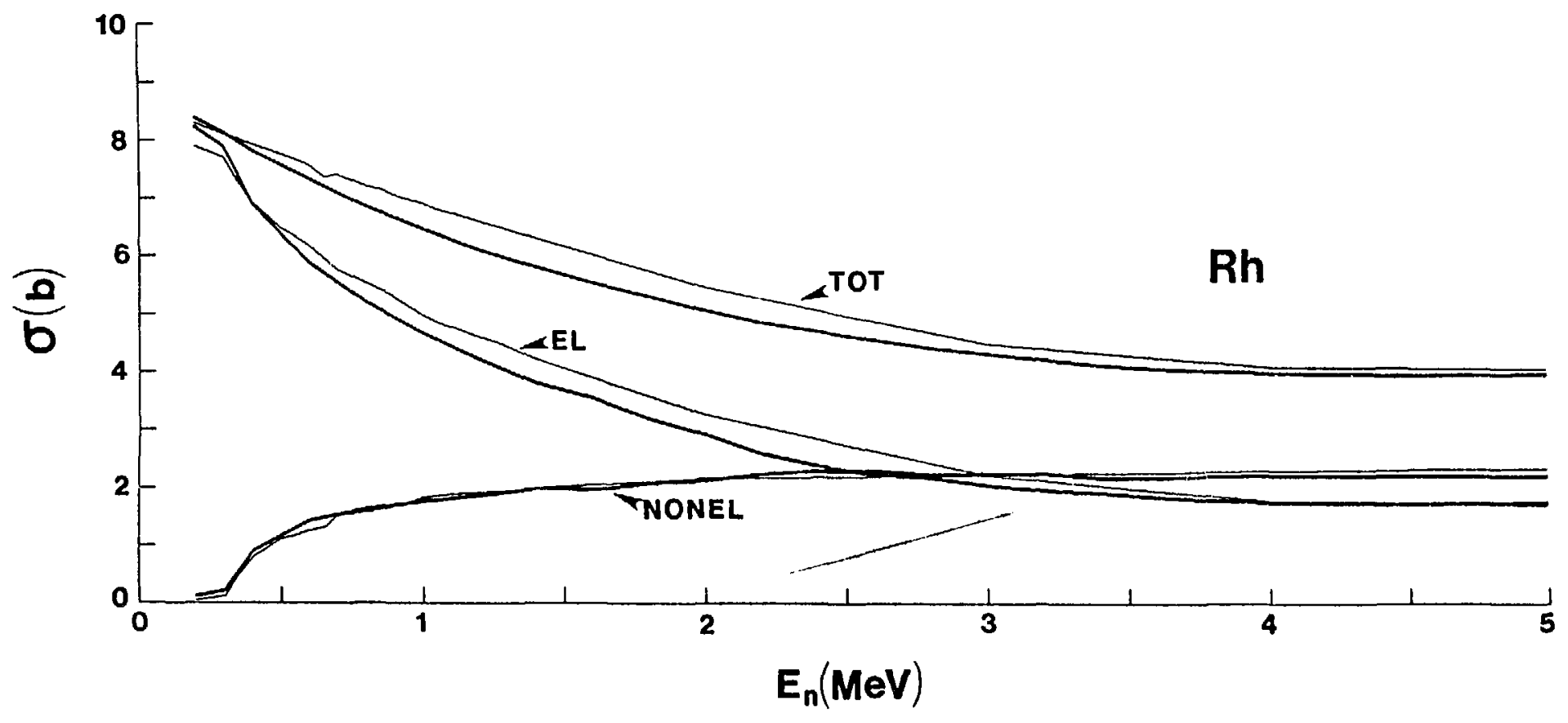

Fig. 5. Comparison of Measured and Evaluated Neutron Total, Elastic-Scattering and Nonelastic Cross Sections of ${ }^{103} \mathrm{Rh}$. The heavy curves are "eyeguldes" constructed through the present measured and calculated results. The 11 ght curves indicate the comparable quantities taken from ENDF/B-V4. 


\section{ACKNOWLEDGEMENTS}

The authors are indebted to Drs. P. A. Moldauer and W. P. Poenitz for many helpful discussions and for the provision of pre-publication data. We are also indebted to $\mathrm{Dr}$. E. Pennington for h1s assistance in handilng the ENDF/B-V file system. 


\section{REFERENCES}

1. A. Smith, P. Guenther and J. Whalen, Argonne National Laboratory Report, ANL/NDM-71 (1982).

2. A. Smith and P. Guenther, Argonne National Laboratory Report, ANL/NDM-66 (1982).

3. A. B. Smith, to be published.

4. Evaluated Nuclear Data File-B, Version-V, Brookhaven National Laboratory Report, ENDF-201 (1979), Compiled by R. Kinsey.

5. W. P. Poenitz and J. F. Whalen, to be published.

6. A. Smith, P. Guenther, R. Holt and J. Whalen, Argonne National Laboratory Report, ANL/NDM-43 (1973).

7. D. Reitmann, E. Barnard, D. Jones and J. Malan, Proc. Conf. on Nucl. Cross Sections and Technology, NBS Special Pub. 425, Vol. 2 (1975).

8. A. B. Smith and P, T. Guenther, Argonne National Laboratory Report, ANL/NDM-63 (1982).

9. P. T. Guenther, Elastic and Inelastic Neutron Scattering from the Even Isotopes of Tungsten, Univ. of I1l. Thesis (1977).

10. A. B. Smith, unpublished results (1982).

11. Table of Isotopes, 7th Edition, C. M. Lederer and V. S. Shirley, Eds., John Wiley and Sons, Inc., New York (1978).

12. P. Hodgson, Nuclear Reactions and Nuclear Structure, Clarendon Press, Oxford (1971).

13. J. Rapaport, V. Kulparni and R. Finley, Nuc1. Phys., A330 15 (1979).

14. W. Hauser and H. Feshbach, Phys. Rev., 87366 (1952).

15. P. A. Moldauer, Phys. Rev., C11 426 (1978), also private communication (1982).

16. A. Gilbert and A. Cameron, Can. Jour. of Phys., 431446 (1965).

17. ABAREX, a spherical optical-model program, P. A. Moldauer, private communication (1981).

18. P. A. Moldauer, Nucl. Phys., 4765 (1963). 
TABLE 1. Observed Excitation Energles (1n keV)

\begin{tabular}{lrl}
\hline No. & $E_{x}$, Exp. & Reference 7 \\
\hline 1 & $334 \pm 13^{3 a}$ & $295(3 / 2-), 357(5 / 2-)$ \\
2 & $536 \pm 7$ & $536(5 / 2+)$ \\
3 & $648 \pm 25$ & $607(7 / 2+), 650(5 / 2+), 651(3 / 2+)$ \\
4 & $796 \pm 20$ & $805(1 / 2-)$ \\
5 & $864 \pm 22$ & $847(7 / 20), 881(5 / 2-), 920(9 / 2-)$ \\
6 & $1120 \pm 22$ & $1106(5 / 2-)$ \\
7 & $1279 \pm 50$ & $1251(5 / 2+), 1277(3 / 2-), 1293(9 / 2-)$ \\
8 & $1481 \pm 27$ & \\
9 & $1683 \pm 39$ \\
10 & $1840 \pm 79$ \\
11 & $1991 \pm 71$ \\
12 & $(2050)$ \\
\hline The uncertaint & \\
from the average of a defined as the RMS deviation &
\end{tabular}


Table 2. Optical-Potential Parameters for Rhodiuma

Real Potentialb

$$
\begin{aligned}
& v_{0}=46.896 \mathrm{MeV} \\
& r_{v}^{c}=1.266 \mathrm{~F} \\
& a_{v}=0.686 \mathrm{~F} \\
& \mathrm{Vr}^{2}=75.19 \mathrm{MeV}-\mathrm{F}^{2} \\
& J_{\mathrm{v}} / \mathrm{A}=451.42 \quad \mathrm{MeV}-\mathrm{F}^{3}
\end{aligned}
$$

Imaginary Potentiald

$$
\begin{aligned}
& \mathrm{W}=10.988 \mathrm{NieV} \\
& r_{W}^{c}=1.319 \mathrm{~F} \\
& a_{W}=0.431 \quad F \\
& \text { Wa }=4.74 \text { MeV-F } \\
& J_{W} / A=89.75 \quad M e V-F^{3}
\end{aligned}
$$

also a spin orbit term of the Thomas form with a $6 \mathrm{MeV}$ strength.

${ }^{b}$ Saxon form with energy dependence of $\mathrm{V}=\mathrm{V}_{\mathrm{O}}-$ 0.3 - $\mathrm{E}(\mathrm{MeV})$.

$\mathrm{C}_{\mathrm{A} 11}$ radii expressed as $\mathrm{R}=r \cdot \mathrm{A}^{1 / 3}$.

${ }^{d}$ Saxon-derivative form. 
Table 3. Comparisons with ENDF/B-V

\begin{tabular}{ccc}
\hline & \multicolumn{2}{c}{ ENDF-EXP } \\
ENDE & Totals & Elastics \\
\hline .5 & $+2.3 \%$ & $+1.5 \%$ \\
1.0 & $+6.0 \%$ & $+6.0 \%$ \\
1.5 & $+8.0 \%$ & $+8.6 \%$ \\
2.0 & $+7.3 \%$ & $+10.0 \%$ \\
2.5 & $+6.6 \%$ & $+15.4 \%$ \\
3.0 & $+3.8 \%$ & $+8.6 \%$ \\
3.5 & $+4.6 \%$ & $+5.0 \%$ \\
4.0 & $+2.0 \%$ & $+2.0 \%$ \\
5.0 & $+2.0 \%$ & $-2.0 \%$ \\
\hline
\end{tabular}

